\title{
Design of a Rules-Based Recommendation System Implemented in Prolog for the Management of Electronic Waste from ICT
}

\author{
David Leonardo Dallos Parra', Maryury Julieth Carvajal Camargo', \\ Juan Manuel Sánchez Céspedes ${ }^{1 *}$ \\ 1 Facultad de Ingeniería, Universidad Distrital Francisco José de Caldas, Carrera 7 \# 40B - 53, 110211, \\ Bogotá D.C., Colombia \\ * Corresponding author's email:jmsanchezc@udistrital.edu.co
}

\begin{abstract}
Electronic waste generated from Information and Communication Technologies (ICT) has become a global issue as this represents a negative impact on both environment and human health. Consequently, it is noticeably useful to develop tools to soften such impact. Therefore, this article presents a rules-based system implemented in Prolog aiming at guiding ICT devices users towards good practices on electronic waste management to diminish the negative impact. The methodologies employed include exploratory, descriptive, and experimental. Even though the system developed in Prolog was found to be deficient with user interface, it is also functional and efficient, including features like usability and maintainability. In conclusion, it was found that waste recollection systems may be useful for both environmental management processes in different countries and also positive business opportunities.
\end{abstract}

Keywords: electronic waste, recycling, rules-based system, information and communication technologies, Prolog.

\section{INTRODUCTION}

Electronic waste management has been declared an issue around the world that involves all countries [Egwali and Mouokhome, 2013] given the constant technological development and the high consumption and waste of electronic devices. As an example, 50 million tons of electronic waste was generated by 2018 ; in contrast, the limited number of that waste recycling is limited to only $20 \%$ [Organizacion de las Naciones Unidas, 2019]. In addition, the process of recycling is itself an issue given the potential presence of substances present in an electronic device which may arise to 1000 substances [Jaragh and Boushahri, 2009; Organizacion de las Naciones Unidas, 2019].

Electronic waste can be classified as "ewaste" (Electronical-waste), which are residues from irreparable damage; the other category is "WEEE" (Waste from Electrical and Electronic Equipment), these residues are left for reasons of technological obsolescence, but can still be functional [de Jesús Casas et al., 2015].

Electronic waste generates huge negative impacts on human and environmental health reaching even to water and food supply pollution [Devika, 2010]. Moreover, recycling malpractices like plastic burning to recover valuable metals releases gases that pollute the atmosphere with particulate material [Organizacion de las Naciones Unidas, 2019], which leads to respiratory diseases that may cause death [Afsar et al., 2019]. Researches have proven that the practice of burning plastic releases toxic dioxins that raise the ozone presence at the ground level, reducing the crops between 20\% and 30\% [Plastic Oceans International, 2021].

According to various researches, electronic waste management is an environmental issue and also a business opportunity [Aristizábal-Alzate, González-Manosalva, and Vargas, 2021; Boeni, Silva, and Ott, 2008; Buday-Malik, 2006; Widmer et al., 2005], since with a suitable recycling 
process, base and valuable metals such as iron $(\mathrm{Fe})$, copper $(\mathrm{Cu})$, aluminum $(\mathrm{Al})$, lead $(\mathrm{Pb})$, nickel $(\mathrm{Ni})$, silver $(\mathrm{Ag})$, gold $(\mathrm{Au})$ and palladium $(\mathrm{Pd})$ can be recovered [Aristizábal-Alzate, González-Manosalva, and Vargas, 2021].

While the current development of software has boosted different areas of life, the purpose of this research was the development of a RulesBase System written via Prolog logic programming language to provide users' recommendations regarding the management of ICT devices according to the characteristics of the devices employed. Recycling good practices by users constitutes a start point that will ostensibly mitigate negative impacts of such residues in the environment and people's health.

The necessity of a system like the one proposed in this article captures a special requirement of management that includes interaction among different operators with substantial technical and logical resources [Tsitomeneas, Kokkosis, and Charitopoulos, 2014]. In addition to showing the steps to follow to avoid those actions that harm the environment.

\section{RULES-BASED SYSTEM}

Rules-Based Systems (RBS), also known as "Expert Systems" aims at storing the knowledge of a human expert in a domain or area to pose such knowledge to be interactively used employing Artificial Intelligence techniques to provide applicable solutions in a specific subject or matter in addition to generating new knowledge [Badaro, Ibañez, and Agüero, 2013].

When representing the knowledge emanating from a human expert, Artificial Intelligence techniques have been widely employed in fields like medicine [Van Biesen et al., 1998; Frame et al., 1998; Zolnoori, Zarandi, and Moin, 2012], social sciences [Corrêa et al., 2014; Erdoğan and Kaya, 2020; Longley, 1987], administration and business [Chen and Miao, 2006; Hadavandi et al., 2011; Yang et al., 2018], and agriculture [Barbon et al., 2016; Wang, Kwok, and Ip, 2010; Wang, Ye, and Yang, 2020], among others.

The structure of an RBS is built on three pillars: a knowledge base, a body of facts, and an inference engine. The knowledge base consists of a set of rules given by conditional expressions in the form IF, cause, THEN, effect; the cause is called the antecedent, and the effect is the consequent. Thus, an inference is produced in a given input, the output can be triggered [Liu and Gegov, 2016]. Even though the rules are expressed in conditional sentences those describe only the certainties of an expert instead of logical implications. The basis of facts is the relevant data related to a concrete issue [Diez, 2016]. The basis of knowledge and facts is dynamic since it adapts through the same system [Diez, 2016]. The inference engine is responsible for searching for information and relations in the base knowledge and provides answers, predictions, or recommendations as a human being would [Kadhim, Alam, and Kaur, 2013].

\section{RELATED STUDIES}

Since electronic waste is a global concern, several projects have been undertaken aiming at regulating and supporting recycling processes and the reuse of components obtained from disposable items.

Studies are focused on the environmental impact those residues have unleashed, as in [Devika, 2010], where the components of the residues are labeled as dangerous because of the mix of different toxins harmful to the environment and people.

There are developments in managing electronic waste around the world. Countries like Holland [Leijting, 2012] have developed various cooling and freezing methods and other processes in the life cycle to avoid emissions of gases into the atmosphere. Thailand and other Asian countries developed a study [Sathaporn and Ruth, 2012] exposing that one of the main reasons to participate in recycling and reuse of electronic devices is rooted in the monetary compensation, which needs evaluation to determine the balance between the compensation and recycling operation costs.

Eastern countries have implemented reforms that make the manufacturing industries accept discarded devices to apply suitable processing for reuse and recycling. Even though this includes additional charges. South Korea and Taiwan have policies to oblige to regulate the management of such discarded devices and materials.

A "Reverse Logistics" system was applied in [Sathaporn and Ruth, 2012] aiming to manage the flow of products for consumers to make 
possible the reuse of such products at the end of the profitable life cycle through reuse, recycling, remanufacturing, and disposal. All these allow recovering precious metals. Nevertheless, a series of concerns have arisen caused by the lack of knowledge about environmental damage and recycling processes, including unsafe materials management, especially in the informal setting with small recycler groups.

The investigation carried out by Annie, Imouokhome [Egwali and Mouokhome, 2013] describes the challenges of waste management in Nigeria, a country with high rates of informality and poverty, besides suffering from exporting large quantities of electronic and electrical waste where the recycling processes is carried out in poor conditions and harmful for recycler's health.

On the other hand, there are different policies in Latin American countries that change the process of electronic waste management. For instance, in Colombia, the "Computadores para Educar" (Computers to Educate) initiative aims at extending the life-cycle of computers discarded by donating to less privileged communities to provide access to informatics tools like the Internet, office software, among others. Researchers have suggested that to succeed in managing ICT waste, it is necessary to involve participants like local governments, ICT companies, and users [Boeni, Silva, and Ott, 2008]. Bartolo and Urbina [Bartolo Pinzón Jonathan Urbina Guerra, n.d.] display statistical information related to waste management in Colombia. It is estimated that between 2009 to 2015, the number of WEEE amounted to more than 884 thousand tons throughout the country.

The project REMATRONIC in Brazil [Silva et al., 2015] was created to recover precious metals from printed circuit boards. The employment of technologies aims at implementing mechanisms including added value in the recovery and recycling chain of discarded electronic devices through "reverse logistics".

A multi-criteria decision-making problem is addressed in [Andarani and Budiawan, 2015] to determine the optimal localization of such centers. Throughout the study, several influencing variables were defined concerning the selection of the most optimal place that simultaneously minimizes the economic and social impacts. Each criterion or variable is a measure that guides the decision toward an optimality point, and building base solutions takes from the needs and preferences. This research showed positive results regarding site selection; nevertheless, as a recommendation, it is suggested to specify the available area to place the collection center and the relevant legal approach.

Research document [Xu et al., 2014] aimed to develop a model to predict the population behavior toward recycling. The results showed that the most influencing factors are attitude, control, and social norms. However, some results displayed that users are more concerned about the incoming generations while others hope to profit or obtain social retribution. The research model employed nine factors, including a graphic construction, as observed in Figure 1.

The model employs undependable variables like attitude, subjective norms, and control of the perceived behavior. Besides, experience, rulesbased promotion, and environmental knowledge are the moderating variables. Finally, the dependent variable is the intention of recycling. Environmental knowledge has a moderating role in the relationship between attitude and recycling intention. It is said that when the knowledge is



Figure 1. Model of factors of influence about recycling intention. Source: adapted from [Xu et al., 2014] 
greater, then it is more likely to correctly distinguish between an informal and a suitable way of recycling discarded devices. Nevertheless, if the environmental damage is insufficiently known, the individual may be attracted to illegal programs of collection motivated by the economic benefits behind [Xu et al., 2014].

\section{METHODOLOGY}

From bibliographic review to the implementation of Prolog, different stages were employed for developing the system to gather all the relevant information for designing the rule base and facts for operating the recommender system. The following describes approaches and methodological aspects employed during the project's elaboration.

\section{Methodological approach}

An exploratory-descriptive approach was carried out for the first part of the research [Hernández Sampieri et al., 2014; Vergel Cabrales, 1997] identifying the environmental impact of electronic waste in various countries, besides the processes undertaken toward efficient and environmentally friendly management.

The second part of the investigation was carried out gathering information concerning the recommended processes for electronic waste and the particular case of the research -electronic waste from ICT quasi-experimental type [Bono Cabre, 2012]. This stage included the rules base system and its development with Prolog and the statement of facts and relevant rules to build up the knowledge-base and then carry out the reasoning process on the data allowing the system testing to see recommendations for cases of devices like the computer.

\section{Methodological aspects}

With the gathered information taken from secondary sources was made and analysis and recount of the situation in various countries around the world to measure the impact of projects and projects undertaken by people in those places to arrive at the management of electronic waste in Colombia.

\section{Methodological instruments}

For the construction and implementation of the knowledge base, it was necessary the contribution of diverse methodological resources detailed here.

\section{Bibliographic review}

Through consultation via electronic and governmental databases, different articles were reviewed to obtain the theoretical framework and background referring to the environmental impact and repercussions in human life of electronic wastes. Likewise, there are projects aiming at reducing the level of polluting gas emissions or recycling support systems. Nevertheless, it is crucial to generate mechanisms to keep citizens informed and receive recommendations about the recycling or reuse of the discarded elements, which is the focus of this article.

\section{Development in Prolog}

The base of facts that specifies technical guidelines for the management of Electrical and Electronic Waste was built from the documents issued by the Ministry of Environment, Housing and Land Development [Ministerio de Ambiente Vivienda Y Desarrollo Territorial, 2010] and the Colombian Ministry for Environment and Sustainable Development Colombia [Ministerio de Ambiente y Desarrollo Sostenible, 2017].

From the previous, the recycling process has different stages, but for the design and development of the system were defined five large phases. The first is the "Use" which refers to individuals that do the recycling process and may include individuals, households, and public or private entities. The research was framed only for ordinary individuals. Next phase is the "collection which" considers only three collection types: manufacturer (company, device); for instance, ( $\mathrm{Hp}$, computer), manufacturer (Hp, printer), Manufacturer (Lenovo, computer).

Then, it is defined the distributor with the following elements, the first parameter value is the name of the distributor, the second is the brand, and the last is the generic name of the product. Distributor (Distributor name, Equipment brand Product)

The user is asked about the way he wants the collection employing the following rule. 
Collection:-

Write (press ffor direct collection with

the manufacturer, press $d$ for collection

with the distributor and $r$ for collection

with the collectorRAEE'), $n l$, read(Reply),

$n l(($ Reply $==f)->$ recoFabricante;

(Respuesta $==d)$->recodistribuidor;

(Respuesta $==r$ )->recoraee;fail).

As observed, the user is asked about the collection way: directly with the manufacturer, the distributor, or with collectorRAEE. This is effective when reading the option through the function read. If the user chooses the manufacturer, the name of the manufacturer needs to be entered (brand) with the product's generic name; with these data, the system does the verification with the known data; if the fact exists, the program will advise the user to contact the distributor. The process for the distributor is similar, the user needs to enter the name of the distributor, brand, and product name, while for collectorRAEE the system will ask if the user wants reuse or transportation.

The third phase is "reuse". This phase is optional depending on the equipment status for recycling; for managing "reuse" it is first necessary to choose collectorRAEEE which is managed with the following rule.

reuse:-

write (' if the equipment is functional press $v$

to retrieve information to sell or d to donate'), $n l$, $\operatorname{read}($ Reply), $n l,(($ Reply $==v)->$ sell; $($ Reply $==d)$ - >donate:fail).

As observed, if the equipment is functional, the user has two options to make it reusable by selling or donating it. Both options also included rules which retrieve information to enable the user to perform such action; the definition of rules is as follows.

Sell:-

Write('you can sell of your equipment via web using olx,

Linio and Mercado Libre.'), nl, ask

Donate:-

Write('for the donation of your product you can take it to EcoPunto,

LCS Colombia'), nl, ask.

The fourth phase is "Transport" in which users receive recommendations for packaging depending on the type of product and the container to do it. This part is modeled with rules, and the first one is to ask the user about the product type: a monitor, printer, etc.

If the product is a TRC tv or screen, the user needs to choose the container for packaging under the following options: box, stowage, or no container. If the user selects a box, there should be certain inspections on the product under the following rules.
Box:-
Write (" if it is more than one TRC tv or
monitor,
please pack one per box, before packaging
please check, if
the tv tube is broken press $b$, if the tv or
monitor has a cable
press $l$, if both situations happen press $f$, if
none of the cases happens
press $r$, your packaging is complete'), $n l$
read(Reply), $n l$,
((Reply $==b), n l->$ brokentube
(Reply $==l)$-> withcable
(Reply==f) $->$ both;
(Reply $==r) \rightarrow$ recycling;fail).

For each consideration there are rules included and given to the user step by step until completing the packaging process. For instance, how to do the packaging when having broken pieces of a monitor or directions on how to transport a tv when it has a cable, etc.

There is a different rule when, for instance, the user selects stowage since additional considerations should be regarded including if the item is broken or if it has a cable, the "withcable" rule used with the box. Finally, a rule is designed for cases when no container is found with the proper considerations of the case.

Another rule was designed when the product is a printer, fax, copier machine, or other equipment for packaging in boxes, stowage, or no container; however, it is necessary to look into the exceptional properties of each device.

The last phase corresponds to recycling since this requires specialized procedures. At this stage, the user will only receive information related to what has to be done at that point, which may include foundry to obtain ferrous materials; thermal and chemical refining to recover noble and nonferrous metals; incineration techniques when resulting waste is worthless, are no usable, or with dangerous content. 
The complete flowchart of both information and processes is summarized in Figure 2.

Evaluation of the system: The evaluation of the system took a qualitative and quantitative mixed approach. 10 Experts were surveyed asking to evaluate from 1 to 5 points, where 1 indicates that the requirement does not comply with the attribute, and 5 indicates full compliance with the attribute. The attributes were functionality, usability, maintainability, effectiveness, and user interface.

\section{RESULTS}

For testing the system design, it was simulated the need to receive information for a proper disposition of a personal computer which according to statistics has a five-year life cycle. Figure 3 displays the graphic interface to enter the data of the electronic device. If the device is functional the system can suggest a place for donation, as shown in Figure 4. Figures 5 and 6 display recommendations for users for packaging devices. Once the packaging is complete, information on



Figure 2. Flowchart of the system 
recycling processes RAEE is presented to user according to Figure 7.

\section{Quantitative evaluation}

Figure 8 presents the final outcome of expert's quantitative evaluation. Affectivity and functionality criteria obtained a better score, followed by maintainability and usability; the criterion with lowest score was the graphic interface. The qualitative evaluation explains the reasons for this evaluation.

\section{Qualitative evaluation}

Below in review are presented the comments of experts.

Functionality. A positive point is a feasibility to add, remove, and upgrade different facts and rules in the knowledge base as the system works correctly.

Usability. The system is not very intuitive, but the time of learning is short, and its consequent use becomes easy for users.

Maintainability. The system easily allows adding elements to the rules and facts, but adding new procedures increases the level of complexity since it is necessary the definition and addition sequences of the information flow. Even though other systems may be more efficient, employing fuzzy logic for the first-order logic using Prolog is also effective for the system.

Efficacy. The system can generate relevant recommendations after the sequence of questions to determine the device features.

\section{Enter the name of the brand (lower case and ending with a full stop. Enter the name of the brand (lower case and ending with a full stop). Hp \\ Enter the name of the product (lower case and ending with full stop, example: computer) I : computer}

User interface. Directly, the system provides a user-friendly graphical console-style interface, but it is not so intuitive making it a little tedious.

In conclusion, the system meets the defined objectives and operates correctly, allowing the addition of new facts and rules, which is a standpoint for updating new recommendations and rules regarding the management of electronic waste. However, it is not remarkably friendly when it comes to process upgrades. Besides, when adding criteria like economic factors, or another type of stakeholders -which makes the option selection may not be so clearly defined- it will not be so efficient since the system operates with the limitations of classical logic, which is less effective compared to fuzzy logic.

Even though the use of the system is easy, the fact of the user interface works through a command console makes it susceptible to not being so user-friendly. For this reason, for further investigations, it is recommended the development of new more maintainable, and more user-friendly systems.

\section{CONCLUSIONS}

Systems that manage electronic waste must include devices complete life-cycle to consider different alternatives to avoid environmental pollution caused by the mismanagement of resources and inner components of household appliances. Recycling and reconditioning equipment for reuse is optimal to prevent environmental damage during the manufacturing of elements, mining activities, consumption of resources, and greenhouse gasses emissions. Directives, standards, and more should carry out controls to prevent the use of difficult to recycle and disassemble

If the equipment is functional Press $v$ to receive information To sell it, $d$ for donation.

For the donation of your product take it to EcoComputo, ICS Colombia

Figure 3. Data entry of electronic device

Figure 4. Recommendation for donation 
Please choose a container

for packaging the product

press c for boxes, e for stowage,

$\mathrm{n}$ in case of no container needed

I : c.

If there is more than one tv or TRC monitor

Please pack one per box, before packaging it check if the tv or monitor has the tube broken then press $b$

if the tv or monitor has its cable, please press 1 , in case of having both scenarios press $f$, if none of the cases apply, the packaging is complete

press $r$

Figure 5. Packaging of monitors

products at the end of the life-cycle and choose reusable elements in addition to applying extended producer liability to reduce, recycle and recover electronic waste.

Currently, waste management represents a business opportunity for different operators which is misused by invasive and polluting procedures like incineration or items disposal in landfills.

The designed system meets the functional requirements but is also crucial the generation of new applications that easily allow upgrades toward new requirements and promote the end-user to employ such systems.
Please have on hand plastic or bubble wrap And pieces of cardboard, then place the first tv standing and looking aside, place on top a piece of cardboard if you need to place a second tv if you place it behind, please put the piece of cardboard in the back side. bear in mind that the maximum is three tv sets wide and tall, once the process is complete wrap all using plastic or bubble wrap, the packaging is finished press $r$

Figure 6. Packaging of more than 1 device

Foundry: it refers to foundry and recycling of ferrous metals.

Thermal and chemical refining: it refers to recovery of noble metals, non-ferrous contained in computer cards with printed circuit boards and other electrical and electronic wastes through thermal and chemical processes.

Incineration: valueless waste no usable or with dangerous content are incinerated under high technical standard procedures that allow the recovery of energetic value.

Figure 7. Information on recycling process

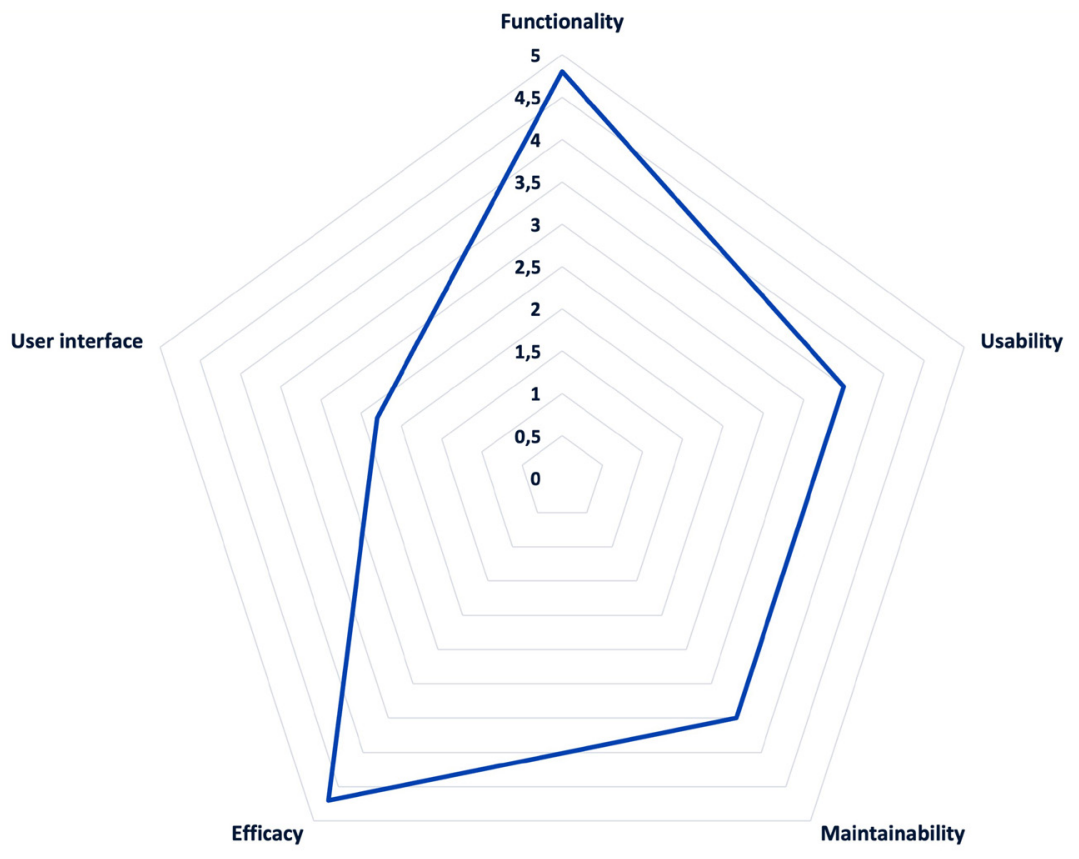

Figure 8. Evaluation of the system 


\section{REFERENCES}

1. Afsar, B et al. 2019. Air Pollution and Kidney Disease: Review of Current Evidence. Clinical Kidney Journal 12(1): 19-32.

2. Andarani, P, and W Budiawan. 2015. Multicriteria Decision Analysis for Optimizing Site Selection of Electronic and Electricity Equipment Waste Dismantling and Sorting Facility (Case Study: In Indonesia, Using AHP). In 2015 International Conference on Science in Information Technology (ICSITech), , 264-69.

3. Aristizábal-Alzate, Carlos E., José L. GonzálezManosalva, and Andrés F. Vargas. 2021. Revalorización de Residuos de Equipos Eléctricos y Electrónicos En Colombia: Una Alternativa Para La Obtención de Metales Preciosos y Metales Para La Industria. TecnoLógicas 24(51): e1740.

4. Badaro, Sebastian, Leonardo Javier Ibañez, and Martín Agüero. 2013. SISTEMAS EXPERTOS: Fundamentos, Metodologías y Aplicaciones. Ciencia y Tecnología 1(13): 349-64.

5. Barbon, A.P.A.C. et al. 2016. Storage Time Prediction of Pork by Computational Intelligence. Computers and Electronics in Agriculture 127: 368-75.

6. Bartolo Pinzón Jonathan Urbina Guerra, Jessica Kimberly. Estado De La Gestión De Residuos De Aparatos Eléctricos Y Electrónicos En Colombia Atendiendo Al Marco De Convenios, Acuerdos Y Estrategias De Gestión En El Contexto Internacional State Of Waste Of Electrical And Electronic Management In Colombia Attendin.

7. Van Biesen, W, G Sieben, N Lameire, and R Vanholder. 1998. Application of Kohonen Neural Networks for the Non-Morphological Distinction between Glomerular and Tubular Renal Disease. Nephrology Dialysis Transplantation 13(1): 59-66.

8. Boeni, Heinz, Uca Silva, and Daniel Ott. 2008. E-Waste Recycling in Latin America: Overview, Challenges and Potential. Proceedings of the 2008 Global Symposium on Recycling, Waste Treatment and Clean Technology, REWAS 2008: 665-73.

9. Bono Cabre, Roser. 2012. Universidad de Barcelona. Facultad de Psicología. Diseños Cuasi-Experimentales y Longitudinales.

10. Buday-Malik, A. 2006. Key Questions of ICTi Waste Management in Hungary and in Slovenia. In Proceedings of the 13th CIRP International Conference on Life Cycle Engineering, LCE 2006, Katholieke Universiteit Leuven, 489-96.

11. Chen, Z C, and Z Miao. 2006. An Intelligent Approach to Non-Constant Feed Rate Determination for High-Performance 2D CNC Milling. International Journal of Manufacturing Technology and Management 9(3-4): 219-36.

12. Corrêa, A S, A de Assis Mota, L T M Mota, and P L P
Corrêa. 2014. A Fuzzy Rule-Based System to Assess e-Government Technical Interoperability Maturity Level. Transforming Government: People, Process and Policy 8(3): 335-56.

13. Devika, S. 2010. Environmental Impact of Improper Disposal of Electronic Waste. In Recent Advances in Space Technology Services and Climate Change 2010 (RSTS CC-2010), , 29-31.

14. Diez, Juan José. 2016. Sistemas Inteligentes T6: Sistemas Basados En Reglas. : 40.

15. Egwali, A. O., and F. A. I Mouokhome. 2013. Managing the Challenges of E-Waste Recycling in Nigeria. In Science and Information Conference. IEEE, , 689-95.

16. Erdoğan, M, and İ Kaya. 2020. A Systematic Approach to Evaluate Risks and Failures of Public Transport Systems with a Real Case Study for Bus Rapid System in Istanbul. Sustainable Cities and Society 53.

17. Frame, A J et al. 1998. A Comparison of Computer Based Classification Methods Applied to the Detection of Microaneurysms in Ophthalmic Fluorescein Angiograms. Computers in Biology and Medicine 28(3): 225-38.

18. Hadavandi, E, A Ghanbari, K Shahanaghi, and S Abbasian-Naghneh. 2011. Tourist Arrival Forecasting by Evolutionary Fuzzy Systems. Tourism Management 32(5): 1196-1203.

19. Hernández Sampieri, Roberto, Carlos Fernández Collado, María del Pilar Baptista Lucio, and Pilar Baptista Lucio. 2014. McGraw-Hill Metodología de La Investigación. Sexta. México D.F.: McGraw-Hill / Interamericana Editores, S.A. De C.V.

20. Jaragh, Mansour, and Jenan Boushahri. 2009. The E-Waste Impact. In Proceedings of the First Kuwait Conference on E-Services and e-Systems, eConf '09, New York, NY, USA: Association for Computing Machinery.

21. de Jesús Casas, José et al. 2015. Priorización Multicriterio de Un Residuo de Aparato Eléctrico y Electrónico. Ingeniería y desarrollo 33(2): 172-97.

22. Kadhim, Mohammed Abbas, M Afshar Alam, and Harleen Kaur. 2013. Design and Implementation of Intelligent Agent and Diagnosis Domain Tool for Rule-Based Expert System. In 2013 International Conference on Machine Intelligence and Research Advancement, , 619-22.

23. Leijting, Jorrit. 2012. The Benefits of E-Waste Recycling in The Netherlands. In 2012 Electronics Goes Green 2012+, , 1-4.

24. Liu, Han, and Alexander Gegov. 2016. Rule Based Systems and Networks: Deterministic and Fuzzy Approaches. In 2016 IEEE 8th International Conference on Intelligent Systems (IS), , 316-21.

25. Longley, D. 1987. Expert Systems Applied to the 
Analysis of Key Management Schemes. Computers and Security 6(1): 54-67.

26. Ministerio de Ambiente Vivienda Y Desarrollo Territorial. 2010. Lineamientos Técnicos Para El Manejo de Residuos de Aparatos Eléctricos y Electrónicos.

27. Ministerio de Ambiente y Desarrollo Sostenible. 2017. Politica Nacional: Gestion Integral De Residuos De Aparatos Electricos Y Electronicos.

28. Organizacion de las Naciones Unidas. 2019. Los Desechos Electrónicos, Una Oportunidad de Oro Para El Trabajo Decente | Noticias ONU. Noticionas ONU.

29. Plastic Oceans International. 2021. La Quema de Plástico Agrava La Contaminación Del Aire. plasticoceans.org.

30. Sathaporn, Monprapussorn, and Banomyong Ruth. 2012. Reverser Logistic System of Electronic Waste in Thailand: An Environmental Perspective. In 2012 Electronics Goes Green 2012+, , 1-5.

31. Silva, Jose Rocha et al. 2015. Rematronic: Project to Recovery Precious Metals from Electronic Waste. In MEDES '15: Proceedings of the 7th International Conference on Management of Computational and Collective IntElligence in Digital EcoSystems, 221-227.

32. Tsitomeneas, Stefanos Th., Apostolos I Kokkosis, and Angelos G Charitopoulos. 2014. Legislation, Design and Management of the Electrical and Electronic Waste (e-Waste) Procedures. In MedPower
$2014,, 1-5$.

33. Vergel Cabrales, Gustavo. 1997. Metodología Un Manual Para La Elaboración de Diseños y Proyectos de Investigación. Cuarta.

34. Wang, L, S K Kwok, and W H Ip. 2010. A Radio Frequency Identification and Sensor-Based System for the Transportation of Food. Journal of Food Engineering 101(1): 120-29.

35. Wang, Y.-M., F.-F. Ye, and L.-H. Yang. 2020. Extended Belief Rule Based System with Joint Learning for Environmental Governance Cost Prediction. Ecological Indicators 111.

36. Widmer, R et al. 2005. Global Perspectives on EWaste. Environmental Impact Assessment Review 25(5 SPEC. ISS.): 436-58.

37. Xu, F, X Wang, X Sun, and AAbdullah. 2014. Influencing Factors and Moderating Factors of Consumers' Intentions to Participate in e-Waste Recycling. In 2014 11th International Conference on Service Systems and Service Management (ICSSSM), , 1-6.

38. Yang, L.-H., Y.-M. Wang, J Liu, and L Martínez. 2018. A Joint Optimization Method on Parameter and Structure for Belief-Rule-Based Systems. Knowledge-Based Systems 142: 220-40.

39. Zolnoori, M, M H F Zarandi, and M Moin. 2012. Application of Intelligent Systems in Asthma Disease: Designing a Fuzzy Rule-Based System for Evaluating Level of Asthma Exacerbation. Journal of Medical Systems 36(4): 2071-83. 